\title{
Controls on the hydraulic geometry of alluvial channels: bank stability to gravitational failure, the critical-flow hypothesis, and conservation of mass and energy
}

\author{
Jon D. Pelletier \\ Department of Geosciences, The University of Arizona, 1040 East Fourth Street, Tucson, \\ Arizona 85721-0077, USA
}

Correspondence: Jon D. Pelletier (jdpellet@email.arizona.edu)

Received: 28 May 2020 - Discussion started: 22 June 2020

Revised: 11 December 2020 - Accepted: 24 February 2021 - Published: 26 April 2021

\begin{abstract}
The bank-full depths, widths, depth-averaged water velocities, and along-channel slopes of alluvial channels are approximately power-law functions of bank-full discharge across many orders of magnitude. What mechanisms give rise to these patterns is one of the central questions of fluvial geomorphology. Here it is proposed that the bank-full depths of alluvial channels are partially controlled by the maximum heights of gravitationally stable channel banks, which depend on bank material cohesion and hence on clay content. The bank-full depths predicted by a bank-stability model correlate with observed bank-full depths estimated from the bends in the stage-discharge rating curves of 387 U.S. Geological Survey gaging stations in the Mississippi River basin. It is further proposed that depth-averaged water velocities scale with bank-full depths as a result of a self-regulatory feedback among water flow, relative roughness, and channel-bed morphology that limits depthaveraged water velocities to within a relatively narrow range associated with Froude numbers that have a weak inverse relationship to bank-full discharge. Given these constraints on channel depths and water velocities, bankfull widths and along-channel slopes consistent with observations follow by conservation of mass and energy of water flow.
\end{abstract}

\section{Introduction}

The bank-full depths, $h$, widths, $w$, depth-averaged water velocities, $v$, and along-channel slopes, $S$, of alluvial channels exhibit power-law relationships with bank-full discharge, $Q$ :

$h \propto Q^{k}, w \propto Q^{b}, v \propto Q^{m}, S \propto Q^{z}$,

where $k \approx 0.4, b \approx 0.5, m \approx 0.1$, and $z \approx-0.4$ (Leopold and Maddock, 1953). Many studies have proposed a processbased understanding of these patterns (see reviews by Ferguson, 1986, and Singh, 2003), but none have achieved widespread acceptance.

Schumm (1960) documented that alluvial channels with sand-rich bed and bank material tend to be wide and shallow, while alluvial channels with silt-and-clay-rich bed and bank material tend to be narrow and deep. Schumm's findings have led nearly all subsequent researchers to consider the resistance of bank material to fluvial erosion to be the key factor controlling alluvial channel width (e.g., Parker, 1979; Eaton and Millar, 2004; Dunne and Jerolmack, 2020). Bank retreat, however, is also driven by gravitational failure (ASCE, 1999), a process that limits bank heights to values that depend on bank material cohesion and hence on clay content. The gravitational failure of channel banks may partially control bank-full depths via a self-regulatory mechanism in which channel incision and/or floodplain deposition tend to increase bank height, triggering bank failure when a critical bank height, dependent on bank material cohesion, is exceeded (Andrews, 1982), thus introducing new sediment into the channel bed that, as it is redistributed by fluvial processes, tends to reduce the channel depth back towards a critical value. This paper demonstrates that bankfull depths predicted by a bank-stability model correlate with observed bank-full depths estimated from the bends in the 
stage-discharge rating curves of 387 U.S. Geological Survey (USGS) gaging stations in the Mississippi River basin (MRB). This analysis supports the hypothesis that the gravitational failure of channel banks partially controls bankfull depths and complements the recent work of Dong et al. (2019) that documented a relationship between bankmaterial texture and the hydraulic geometry of alluvial channels in the Selenga River delta.

Grant (1997) proposed a critical-flow hypothesis in which depth-averaged water velocities are self-regulated via interactions between the water flow and the channel-bed morphology. Grant (1997) argued that in steep $\left(0.01 \mathrm{~m} \mathrm{~m}^{-1}\right)$ channels the Froude number rarely exceeds 1 for extended periods of time due to interactions between the free surface and the bed that result in an approximate balance between forces that accelerate the flow and forces that extract energy from the flow. Such a balance may also extend to coarse-bedded channels, in which the water flow is prone to wave drag associated with flow around bed sediment grains that protrude above the water surface (Wohl, 2013). Wave drag can be expected to be more common in coarse-bedded channels relative to channels with finer bed sediments both because they have relatively large bed roughness elements that more readily protrude above the water surface and because they have a tendency towards shallower flows as a result of their characteristically large width-to-depth ratios (Schumm, 1960).

Central to the critical-flow hypothesis is the existence of a self-regulatory feedback in which an increase in velocity is met with an increase in drag that tends to reduce the velocity and hence the Froude number. Similarly, a decrease in velocity tends to be met with a decrease in drag that tends to increase the velocity. Here it is hypothesized that such a self-regulatory feedback is not limited to steep channels. In less-steep, sand-bedded channels, faster flow tends to facilitate the development of larger and more well-developed bedforms (which tend to form at Froude numbers $\sim 0.1-1$, e.g., Simons and Richardson, 1966) that increase relative roughness and hence drag. The mechanisms of self-regulation and the Froude numbers at which steep and less-steep channels may achieve this self-regulation thus differ, but both are likely to have self-regulatory interactions between the flow and the bed that limit the Froude numbers of bank-full discharges. Consistent with this hypothesis, here it is documented that bank-full Froude numbers, and hence the ratio of depth-averaged water velocities to the square root of bankfull depths, tend to be within a relatively narrow range that has a weak inverse relationship to bank-full discharge.

The bank-full widths of alluvial channels are set by the requirement that channels convey geomorphically effective water discharges. Conservation of mass, together with the clay-content control of bank-full depths and the Froudenumber control of water velocities, thus constrains bank-full widths.

Conservation of energy constrains along-channel slopes. The conversion of gravitational potential energy into the ki- netic energy of water leads to a relationship among alongchannel slopes, bank-full Froude numbers, bank-full depths, and the size of the largest bed roughness elements, which in gravel-bedded channels tend to be bed sediment grains and in sand-bedded channels tend to be ripples and/or dunes.

\section{Methods}

\subsection{Controls on bank-full depths}

The maximum stable height, $h_{\mathrm{c}}$, of an alluvial channel bank subject to gravitational shear failure is proportional to bankmaterial cohesion, $C$ (Taylor, 1937; Terzaghi and Peck, 1967; Hunter and Schuster, 1968; Chen et al., 1969; ASCE, 1999):

$h_{\mathrm{c}}=\frac{N_{\mathrm{s}}}{\rho g} C$,

where $\rho$ is the bulk density of the bank material; $g$ is the acceleration due to gravity; and $N_{\mathrm{s}}$ is a stability parameter dependent on the geometry of the potential failure surface (e.g., planar, log-spiral, or circular), the pore pressure of the bank material (which is governed by the water table position if the pore pressure is assumed to be hydrostatic), and the angles of the bank and of internal friction (see Table 1 for a list of variables).

In order to estimate a reference $N_{\mathrm{S}}$ value appropriate for understanding how gravitational stability may influence the scaling of alluvial channel bank-full depths to discharge, a steep bank (i.e., near-vertical at the top of the bank but decreasing to approximately $45^{\circ}$ near the toe) with an internal friction angle of $35^{\circ}$ (typical for a loamy or clayey sand), near-saturated conditions, and a log-spiral potential failure surface were assumed. Near-saturated conditions are consistent with the fact that gravitational shear failure has been documented to occur most frequently during the falling limbs of flood discharges when pore pressures tend to be associated with near-saturated conditions (e.g., Casagli et al., 1999; Simon et al., 2000). Chen et al. (1969) derived $N_{\mathrm{s}}$ values for prescribed angles of the bank and of internal friction for unsaturated conditions. For a friction angle of $35^{\circ}, N_{\mathrm{S}}$ values in Table 1 of Chen et al. (1969) decrease with increasing bank angle from $N_{\mathrm{s}}=22$ for a $60^{\circ}$ bank to $N_{\mathrm{S}}=12$ for a $75^{\circ}$ bank and $N_{\mathrm{s}}=7.5$ for a vertical bank. Hunter and Schuster (1968) limited their analysis to cases with no internal friction (hence, their absolute $N_{\mathrm{s}}$ values are not applicable here) but documented an approximately 3 -fold decrease in $N_{\mathrm{s}}$ values from unsaturated conditions (i.e., $M=h_{\mathrm{w}} \gamma_{\mathrm{w}} / h_{\mathrm{c}} \gamma^{\prime} \approx 1$, where is $h_{\mathrm{w}}$ is the depth to the water table below the top of the bank, $\gamma_{\mathrm{w}}$ is the unit weight of water, and $\gamma^{\prime}$ is the submerged unit weight of the bank material) to near-saturated conditions (i.e., $M=0$ ). Combining the results of Chen et al. (1969) and Hunter and Schuster (1968) suggests that $N_{\mathrm{S}}$ values for a saturated bank with an internal angle of friction of $35^{\circ}$ vary from approximately 7.3 for a $60^{\circ}$ bank to $N_{\mathrm{s}} \approx 4$ for a $75^{\circ}$ bank and 2.5 for a vertical bank. 
Bank material cohesion varies linearly from 0 (for cohesionless sand) to approximately $90 \mathrm{kPa}$ (for pure clay) for moisture contents in the range of $7 \%$ to $40 \%$ according to a least-squares linear regression of the data from Dafalla (2013) (Fig. S1):

$C \approx(900 \pm 70) p_{\mathrm{c}}$

where the unit of $C$ is $\mathrm{Pa}$ and $p_{\mathrm{c}}$ is in percent. The uncertainty in Eq. (3) is the standard error (i.e., 1 standard deviation) resulting from the regression.

Combining Eqs. (2) and (3) and assuming a bulk density of $1700 \mathrm{~kg} \mathrm{~m}^{-3}$ and a value of $N_{\mathrm{s}} \approx 6$ (corresponding to a near-saturated bank with an angle of approximately $65^{\circ}$, i.e., an average angle for a bank that is near-vertical at the top and decreases to an angle of approximately $45^{\circ}$ near the toe) yields

$h_{\mathrm{c}} \approx 0.35 p_{\mathrm{c}}$.

Absent site-specific data for bank angles, the largest source of uncertainty in the proportionality coefficient in Eq. (4) as applied to specific locations is likely the bank angle, since relatively modest variations in bank angle (e.g., from $90^{\circ}$ to $75^{\circ}$ ) are associated differences in $N_{\mathrm{s}}$ of approximately a factor of 3, i.e., much larger than other sources of uncertainty such as that between cohesion and clay content as quantified by Eq. (3). Section 4 provides discussion on how uncertainty in bank angle and other factors such as bank vegetation limit the precision of Eq. (4) to specific locations. The primary objective of this paper, however, is to document an increase, on average, in bank-full channel depth with increasing bankmaterial clay content:

$h \approx 0.35 p_{\mathrm{c}}$

assuming that bank-full depth is approximately equal to the maximum gravitationally stable bank height.

To test the tendency for channel depth to increase, on average, with increasing bank-material clay content as predicted by Eq. (5), the bank-full depths for 387 USGS gaging stations in the MRB were estimated using the bends in the stagedischarge rating curves (Fig. S2) for each station. Predictions of bank-full depth using Eq. (5) were then compared to the observed bank-full depths derived from the rating curves. The gNATSGO soil database (Soil Survey Staff, 2019) was used to estimate the percent clay content of the floodplain deposits adjacent to each station. This analysis focuses on the MRB because there is no readily available soils database for any other continental-scale river basin that resolves floodplains in comparable detail and is based on a similar richness of field-based soil texture measurements.

The bank-full depth for each USGS gaging station was estimated using the intersection of the linear regressions of peak annual gage height (used as a proxy for stage) to peak annual discharge obtained using the five smallest and five largest discharges in each record (shown as gray circles in the example of Fig. S2). This intersection, or bend, in the stagedischarge rating curve can identify the stage and discharge above which overbank flow occurs (Copeland et al., 2000), provided that the slope of the high-flow linear regression is much smaller than the slope of the low-flow linear regression, which is a signature of the abrupt widening of flows as they transition from in-channel to overbank.

The analysis presented here began by including data from all USGS gaging stations in the MRB with available peak discharge data (U.S. Geological Survey, 2020). Only those stations for which the slope of the high-flow linear regression is at least 5 times smaller than the slope of the low-flow linear regression were retained. In addition, only those stations that have at least 20 years of data, have a contributing area larger than $100 \mathrm{~km}^{2}$, are not located close to major infrastructure (based on an inspection of each station location in Google Earth imagery), and have a resulting bank-full depth of greater than $2 \mathrm{~m}$ were retained. Channels with bank-full depths less $2 \mathrm{~m}$ were removed because such channels tend to be associated with low clay contents that are inherently difficult to estimate in the field (see Sect. 3.1 for more detail on the potential bias associated with estimating low clay contents). In order to further filter out stations where the lowflow linear regression is potentially unrepresentative of the hydraulic behavior of in-channel discharges, only those stations for which the extrapolation of the low-flow linear regression is close to zero flow depth at zero discharge were retained. Stations for which the low-flow regression does not extrapolate to a flow stage close to zero at zero discharge may have gage height data that are not an accurate proxy for flow stage and/or have other data quality issues that preclude an accurate estimate of bank-full depth using the stagedischarge rating curve. What represents close should not be based on an absolute error, e.g., $0.5 \mathrm{~m}$, because such a criterion would require that the low-flow regressions for deep channels be relatively more accurate than those for shallow channels. Here "close" was defined as being within $50 \%$ of the bank-full stage from zero. That is, if the bank-full stage is $5 \mathrm{~m}$, then the extrapolation of the low-flow regression to zero discharge must yield a stage within $2.5 \mathrm{~m}$ of zero in order for that station to be retained in the analysis. Similarly, if the bank-full stage is $2 \mathrm{~m}$, then the extrapolation of the low-flow fit to zero discharge must be within $1 \mathrm{~m}$ of zero. A total of 387 stations met these criteria.

To estimate the floodplain clay content for each of the 387 USGS gaging stations, the depth-averaged percent clay content from soil depths of 5 to $150 \mathrm{~cm}$ was computed for every pixel within the MRB using gNATSGO. These depths were chosen to avoid the soil horizon close the surface (typically the $\mathrm{O}$ and/or A horizon, which may have clay contents reflective of surficial biological processes that are not representative of the rest of the profile) and because soil properties at depths greater than $150 \mathrm{~cm}$ can be inconsistently encoded in U.S. soil databases (Miller and White, 1998). A moving ge- 
ometric mean (averaging distance of $10 \mathrm{~km}$ ) of percent clay content was computed within floodplains mapped by Nardi et al. (2019). Because some USGS gaging stations are located in channels with narrow floodplains that are not resolved in Nardi et al. (2019), the Nardi et al. (2019) floodplain map was augmented with single-pixel-width valleys defined by pixels with contributing areas larger than $100 \mathrm{~km}^{2}$ following a steepest-descent routing of contributing area within the National Map Digital Elevation Model (DEM) (Archuleta et al., 2017). Bank-full depths predicted by Eq. (5) were then compared to observed bank-full depths using a Pearson correlation coefficient, a root-mean-squared error (RMSE), the percentage of values correctly predicted to within a factor of 2 , and a $p$ value that quantifies the likelihood of the null hypothesis that the predicted and observed bank-full depths may be correlated by chance.

To assess the potential impact of errors in measurements of percent clay content on predictions of the maximum stable bank height and therefore of bank-full depth using Eq. (5), synthetic predictions for bank-full depths, $h_{\text {pred,syn, were }}$ generated equal to 0.35 times samples of synthetic percent clay content, $p_{\mathrm{c}, \mathrm{syn}}$, drawn from a lognormal distribution designed to mimic the distribution of bank-full depths of USGS gaging stations in the MRB, plus a normally distributed random error with a mean of zero and standard deviation of $\sigma$ :

$h_{\text {pred,syn }}=0.35\left(p_{\mathrm{c}, \mathrm{syn}}+\sigma \eta\right)$,

where $\eta$ is a normally distributed random variable with a mean of zero and a standard deviation of 1 . For $\sigma=0$, Eq. (6) produces synthetic data precisely equal to Eq. (5). With finite values of $\sigma$, Eq. (6) produces synthetic data with scatter that can be used to assess how errors in percent clay content may affect the relationships between observed and predicted bank-full depths.

\subsection{Controls on depth-averaged water velocities and bank-full widths}

The critical-flow hypothesis implies that bank-full Froude numbers, $F$, are limited to a relatively narrow range of values with an upper limit close to 1 for gravel-bedded channels and a similarly narrow but somewhat lower range of values for sand-bedded channels. In Sect. 3.2 it is demonstrated that this variation in $F$ can be quantified using a power-law relationship between $F$ and $Q$ :

$F \propto Q^{n}$.

The power-law exponents reported in this paper were determined via a least-squares linear regression of the logarithms of the data. The definition of Froude number provides a linkage among depth-averaged bank-full water velocities, bankfull Froude numbers, and bank-full depths:

$v=F \sqrt{g h}$.
Equations (7) and (8) thus constrain the value of $m$ to be

$m=\frac{k}{2}+n$.

The exponent $b$ in the relationship between bank-full width and discharge can be constrained by conservation of mass of water assuming steady, uniform flow, consistent with many previous models for the downstream hydraulic geometry of alluvial channels (e.g., Lindley, 1919; Smith, 1974; Ferguson, 1986; Huang et al., 2004; Julien, 2014):

$b=1-k-m$.

\subsection{Controls on along-channel slopes}

The Darcy-Weisbach equation

$v=\sqrt{\frac{8 g h S}{f}}$,

is based on conservation of energy for steady, uniform flow, i.e., that the gravitational potential energy per unit mass, $g h S$, produces a depth-averaged water velocity associated with a drag force per unit mass exerted by the channel bed on the water equal to $(f / 8) v^{2}$, where $f$ is the friction factor (e.g., Ferguson, 1986). Equation (11) can be rewritten as

$S=\frac{F^{2}}{8} f$.

Here the variable power equation (VPE) of Ferguson (2007) is used to quantify $f$ :

$(8 / f)^{1 / 2}=a_{1} a_{2} \beta^{-1} /\left(a_{1}^{2}+a_{2}^{2} \beta^{-5 / 3}\right)^{1 / 2}$,

where $a_{1}$ and $a_{2}$ are coefficients (equal to 6.1 and 2.4 based on the least-squares minimum error for velocity in the calibration performed by Ferguson, 2007), and $\beta$ is the relative roughness. The VPE equation was chosen because it provides a transition between the Manning-Strickler onethird power scaling of friction factor to relative roughness for $\beta \gg 1$ (nearly all sand-bedded channels and some gravelbedded channels) to a quadratic scaling when $\beta$ is 1 (channels with very coarse beds) that agrees well with available data (Ferguson, 2007).

Relative roughness depends on whether or not bedforms are present. Table S2 of Ohata et al. (2017) identifies the range of $F$ and $d_{50}$ values conducive to ripple and/or dune development in alluvial channels. Of the 3790 data points in the Ohata et al. (2017) dataset, 1574 (42\%) have ripples or dunes, of which $19 \%$ are in the field and the remaining $81 \%$ are in the laboratory. I cross-referenced those results with the Dunne and Jerolmack (2018; hereafter, D\&J) global dataset by drawing a curve in $F$ vs. $d_{50}$ space that separates channels that have ripples and/or dunes from those that do not and assuming the existence of ripples and dunes in channels of the 
D\&J dataset that have $F$ and $d_{50}$ values that sit above and to the left (Fig. 3b) of the envelope curve separating channels with and without ripples and dunes in the Ohata et al. (2017) dataset. Section 3.3 demonstrates that $96 \%$ of channels thus identified in the D\&J global dataset as sand-bedded have $F$ and $d_{50}$ values conducive to ripple and/or dune development and therefore have a roughness that is likely dominated by bedforms rather than by bed sediment grains. The D\&J global dataset includes 789 observations of $d_{50}, S$, and, $h$ and 711 observations of $d_{50}, S, w, h$, and $Q$ drawn from the literature.

For gravel-bedded (and coarser) channels, relative roughness is defined in the calibration of Ferguson (2007) as the ratio of 84th percentile of bed grain diameter to the hydraulic radius. Since the analysis of this paper relates Eq. (13) to data from the D\&J global dataset that uses $d_{50}$ instead than $d_{84}$, it is assumed that $d_{50} \approx d_{84} / 2$, and as $w>10 h$ for all points in the D\&J global dataset, the bank-full hydraulic radius is approximately equal to the bank-full depth. The relative roughness for gravel-bedded channels, $\beta_{\mathrm{g}}$, in the D\&J global dataset can therefore be approximated as

$\beta_{\mathrm{g}} \approx \frac{2 d_{50}}{h}$

For sand-bedded channels, relative roughness can by estimated as follows (Bathurst, 1993):

$\beta_{\mathrm{s}} \approx \frac{1.1 H\left(1-e^{-25 \alpha}\right)}{3 h}$,

where $H$ is the bedform height and $\alpha$ is the ratio of bedform height to length, $L$.

Combining Eqs. (12)-(15) gives an equation for the alongchannel slopes of gravel-bedded channels consistent with conservation of energy:

$S_{\mathrm{g}}=\frac{F^{2}}{a_{1}^{2} a_{2}^{2}}\left(\frac{2 d_{50}}{h}\right)^{2}\left(a_{1}^{2}+a_{2}^{2}\left(\frac{h}{2 d_{50}}\right)^{5 / 3}\right)$,

and an analogous equation for sand-bedded channels:

$$
\begin{aligned}
& S_{\mathrm{s}}=\frac{F^{2}}{a_{1}^{2} a_{2}^{2}}\left(\frac{1.1 H\left(1-e^{-25 \alpha}\right)}{3 h}\right)^{2} \\
& \left(a_{1}^{2}+a_{2}^{2}\left(\frac{3 h}{1.1 H\left(1-e^{-25 \alpha}\right)}\right)^{5 / 3}\right) .
\end{aligned}
$$

The heights and lengths of ripples and dunes can be estimated as follows (Yalin, 1964):

$H \approx \frac{h}{6}\left(1-\frac{\tau_{\mathrm{c}}}{\tau_{0}}\right)$

and

$$
L \approx 1000 d_{50}
$$

Equation (17) therefore can be rewritten in terms of $d_{50} / h$ for a prescribed value of $\alpha$ as

$$
\begin{aligned}
& S_{\mathrm{S}} \approx \frac{F^{2}}{a_{1}^{2} a_{2}^{2}}\left(\frac{18000 \alpha\left(1-e^{-25 \alpha}\right)}{1.1\left(1-\frac{\tau_{\mathrm{c}}}{\tau_{0}}\right)^{2}} \frac{d_{50}}{h}\right)^{2} \\
& \left(a_{1}^{2}+a_{2}^{2}\left(\frac{1.1\left(1-\frac{\tau_{\mathrm{c}}}{\tau_{0}}\right)^{2}}{18000 \alpha\left(1-e^{-25 \alpha}\right)} \frac{h}{d_{50}}\right)^{5 / 3}\right) .
\end{aligned}
$$

\section{Results}

\subsection{Controls on bank-full depths}

Figure 1 illustrates the tendency for the clay contents of floodplain deposits adjacent to many smaller channels in the MRB to be lower than those of larger channels. For example, the North Platte and South Platte rivers have typical floodplain clay contents $<10 \%$, while the Platte River has typical floodplain clay contents of $\approx 10 \%-20 \%$, and the Missouri and Lower Mississippi rivers have typical clay contents of $\approx 20 \%-30 \%$. There are many relatively small channels, however, that have clay contents $>30 \%$ due to clay-rich local bedrock. As such, there is not a precise, one-to-one correlation between clay content and contributing area or discharge but instead a general tendency for channels conveying larger discharges to have more clay-rich floodplain deposits.

Figure 2 a compares the bank-full depths predicted by Eq. (5) to observed bank-full depths estimated from the bends in the stage-discharge rating curves. Predicted bankfull depths have a Pearson correlation coefficient of 0.42 with observed bank-full depths, a RMSE of $1.7 \mathrm{~m}$, and $84 \%$ of the data points are within a factor of 2 of the observed bank-full depth. The $p$ value, i.e., the chance that the correlation between $h_{\text {pred }}$ and $h_{\text {obs }}$ could have occurred by mere chance, is $\sim 10^{-17}$.

Figure $2 b$ and $c$ illustrate the potential impact of errors in percent clay contents on predicted bank-full depths using Eq. (5) with $\sigma=0.06$ and 0.12 (6\% and $12 \%)$, respectively. These $\sigma$ values were chosen because, while gNATSGO does not provide an error estimate, a recent soil property dataset created using machine learning algorithms has an estimated RMSE of $12 \%$ (Ramcharan et al., 2018), and a value half that size allows for the effect of error size to be assessed. For a relatively small error $(\sigma=6 \%)$, there is a spread of values around the $1: 1$ line, with a larger relative spread for smaller clay contents, i.e., a $6 \%$ error results in a $100 \%$ relative error for a percent clay content of $6 \%$ (i.e., $h_{\text {pred,syn }} \approx 2 \mathrm{~m}$ ) but a $50 \%$ relative error for a percent clay content of $12 \%$ (i.e., $h_{\text {pred,syn }} \approx 4 \mathrm{~m}$ ). As the $\sigma$ value increases to $12 \%$, the spread of values around the 1:1 line increases as expected

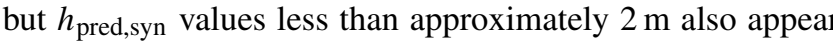




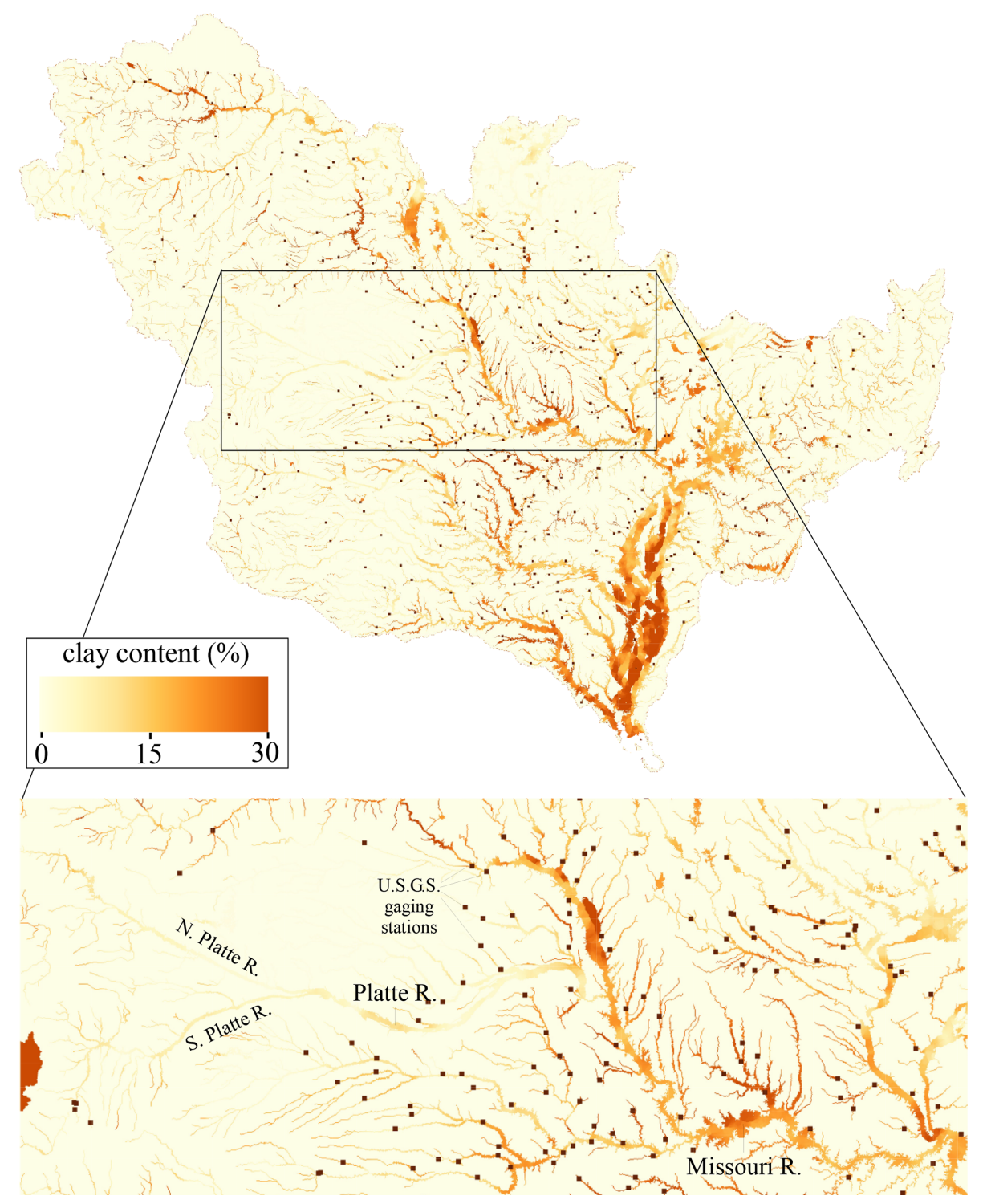

Figure 1. Color map of the average floodplain deposit clay content in the Mississippi River basin. Also shown are the locations of the 387 USGS gaging stations where predicted bank-full depths were computed using Eq. (5) and the observed bank-full depths were estimated based on the bends in the stage-discharge rating curves.

to be biased upward (i.e., the geometric mean of $h_{\text {pred,syn val- }}$ ues deviate from the $1: 1$ line).

This upward bias may be associated with the difficulty of measuring very low clay contents in the field. Clay contents estimated in the field can only be constrained to be within the range from $0 \%$ to $10 \%$ clay. If the actual clay content is close to 0 (e.g., $<1 \%$ ), the clay content estimate is likely to be overestimated by a much larger fraction than would be the case for a larger clay content (e.g., $5 \%$ clay is $400 \%$ greater than $1 \%$ clay but only $50 \%$ lower than $10 \%$ clay). The result may be an upward bias in clay content for clay contents less than approximately $10 \%$, which according to Eq. (5) may be associated with channels less than 2-3 m in bank-full depth.
Channels with bank-full depths less than $2 \mathrm{~m}$ (Sect. 2.1) were excluded from the analysis due to this potential bias.

\subsection{Controls on depth-averaged water velocities and bank-full widths}

Ripples and dunes tend to form at lower Froude numbers in channels with finer bed sediments (Fig. S3). The curve in Fig. S3 used to identify the range of $F$ and $d_{50}$ conditions conducive to ripple and/or dune development is reproduced in Fig. 3, where $96 \%$ of sand-bedded channels in the D\&J global dataset are below the upper limits of $F$ and $d_{50}$ conducive to ripple and/or dune development identified using the Ohata et al. (2017) dataset. As such, it is assumed for 


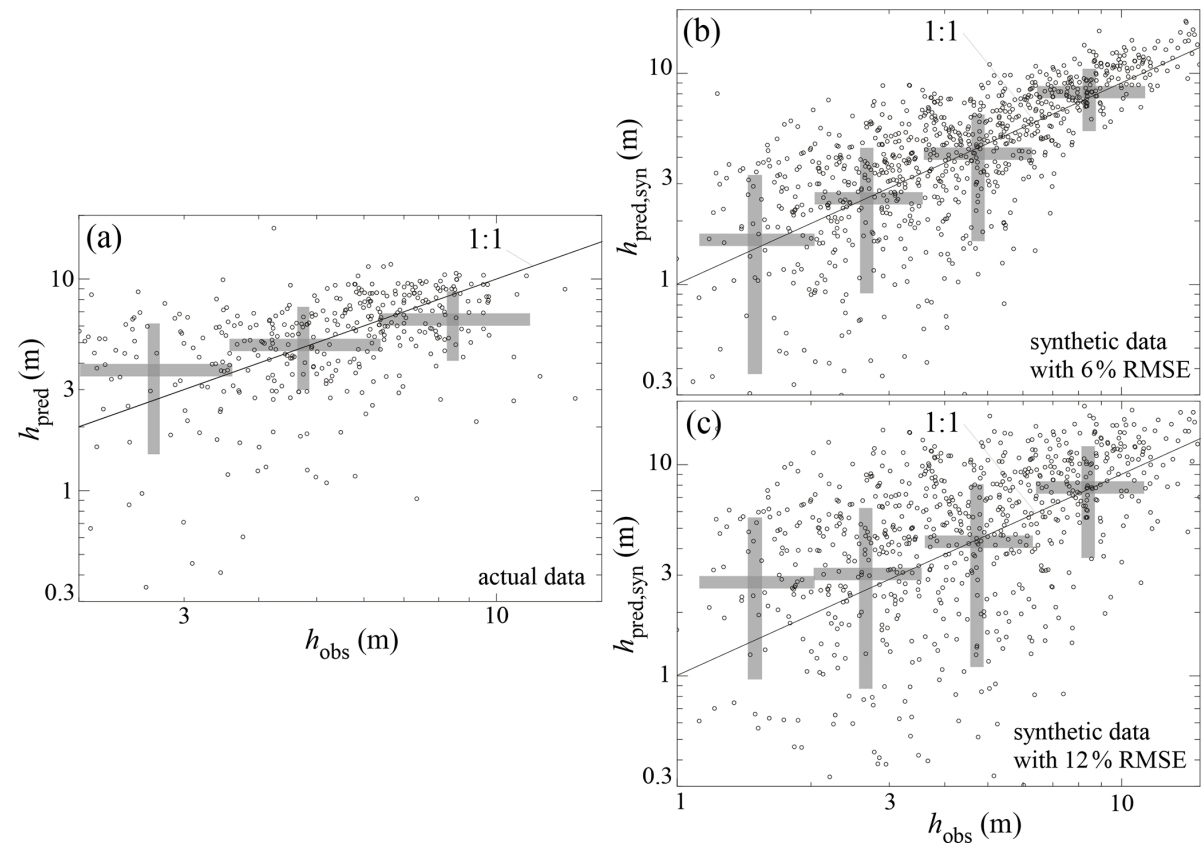

Figure 2. Plots of predicted bank-full depths, $h_{\text {pred }}$, calculated using Eq. (5) versus observed bank-full depths, $h_{\text {obs }}$, estimated based on the bends in the stage-discharge rating curves: (a) actual data and (b, c) synthetic data (Eq. 6) with (b) $\sigma=6 \%$ and (c) $\sigma=12 \%$, respectively. The small open circles are individual data points, and the gray rectangles illustrate the geometric means and standard deviations within each logarithmically spaced bin. The gray rectangles are for visualization purposes only - no analyses are performed on these values.

the purposes of this analysis that sand-bedded channels in the D\&J global dataset are dominated by bedform roughness while gravel-bedded channels in the D\&J global dataset are dominated by grain roughness.

Using the D\&J global dataset, alluvial channel depths and widths scale with bank-full discharges to the $0.402 \pm 0.006$ and $0.512 \pm 0.007$ powers, respectively $\left(R^{2}=0.86\right.$ and 0.89$)$ (Fig. 4). If we take the $-0.116 \pm 0.009$ Froude numberdischarge scaling exponent obtained from least-squares regression to the logarithms of the data (Fig. 3a) and the $0.402 \pm 0.006$ depth-discharge scaling exponent as a starting point, Eqs. (9) and (10) predict a width-discharge exponent of $0.51 \pm 0.01$, i.e., precisely equal to that observed in the D\&J global dataset.

\subsection{Controls on along-channel slopes}

Along-channel slopes predicted by Eqs. (16) and (20) are consistent with observed values in the D\&J global dataset (Pearson correlation coefficient of 0.77) (Fig. 5). For sandbedded channels, in which ripples and/or dunes are likely to be the dominant roughness elements, the predicted values plotted in Fig. 5 assume $\tau_{\mathrm{c}} / \tau_{0} \approx 0$ (consistent with the suspended-load-dominated conditions common in sandbedded channels, Dade and Friend, 2000) and a representative $\alpha$ value of 0.05 (based on the range $0.05-0.1$ reported by Guy et al., 1966). Figure S4 illustrates the sensitivity of the predictions of the along-channel slopes of sand-bedded chan- nels to the presence or absence of bedforms and the assumed value of $\alpha$. For alternative scenarios in which (a) an unrealistically large value $\alpha=0.25$ is assumed and (b) bed grains are assumed to be the dominant roughness elements (i.e., no bedforms are present), Eqs. (16) and (20) predict along-channel slopes that are approximately an order of magnitude above and below observed values, respectively.

\section{Discussion}

The model of this paper posits that floodplain deposit clay contents partially control the maximum stable heights of channel banks. This control is unlikely to result in a precise correlation between clay contents and bank-full channel depths for at least two reasons besides data errors. First, the incised depth of a channel that flows through a section of higher clay content to a section of lower clay content may be more strongly controlled by the lower clay content because the downstream reach may act as the local base level of erosion for the upstream reach. Second, alluvial channels can adjust to spatial variations in bank material cohesion by varying the bank angle in addition to the bank height (Knighton, 1974). For a $35^{\circ}$ angle of internal friction, for example, a bank angle of $60^{\circ}$ has a stability factor, $N_{\mathrm{s}}$, that is approximately 3 times larger than a vertical bank with the same cohesion (e.g., Fig. 3 of Chen et al., 1969). As such, an alluvial channel that flows through a section with less cohesive bank material compared to neighboring sections may adopt a less 

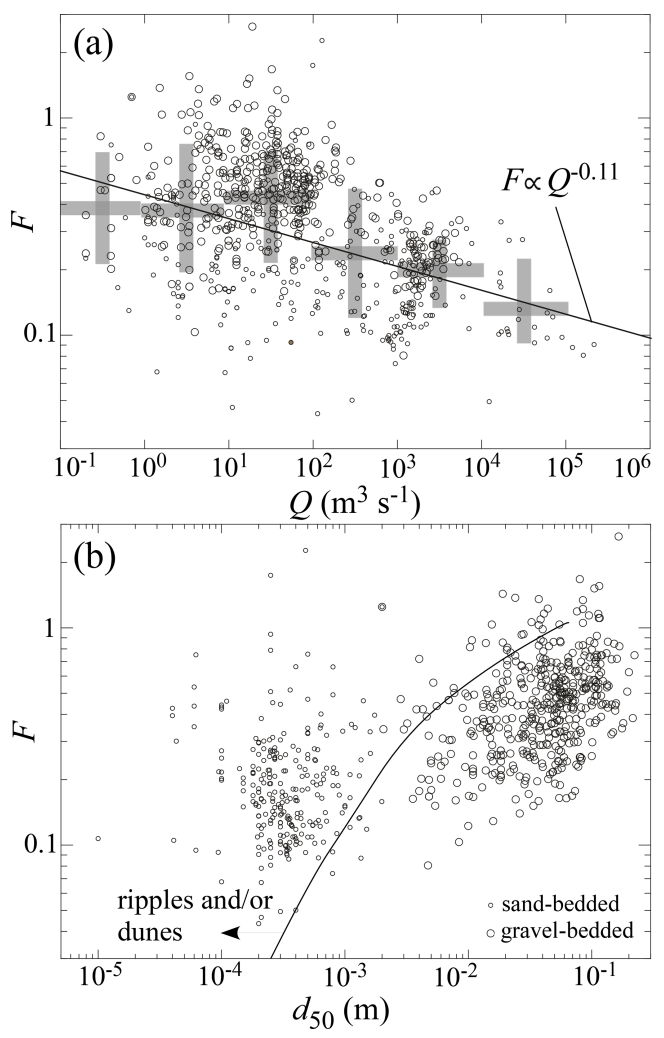

Figure 3. Bank-full Froude number relationships with bank-full discharge and median bed grain diameter. Plot of bank-full Froude number, $F$, as a function of (a) bank-full discharge, $Q$, and (b) median grain size, $d_{50}$, for the Dunne and Jerolmack (2018) global dataset. Small circles correspond to sand-bedded channels $\left(d_{50}<\right.$ $2 \mathrm{~mm}$ ), and large circles correspond to gravel-bedded channels $\left(d_{50}>2 \mathrm{~mm}\right)$. The curve in (b) defining channels that likely have ripples and/or dunes is based on the subset of 3791 field studies and experiments compiled by Ohata et al. (2017) and graphed in Fig. S3.

steep bank (thus increasing the stability factor, $N_{\mathrm{S}}$ ) instead of, or in addition to, becoming wider and shallower in order to minimize variations in channel depth that might otherwise drive large spatial variations in rates of aggradation and incision. Further tests of the model of this paper may require a better understanding of how channel depths and/or bank angles adjust to spatial variations in bank material cohesion through a channel network.

It is also important to consider how potential errors in the data may contribute to the observed scatter in Fig. 2. The estimates of bank-full depths presented here are not exact because gage height (the height of the water above a reference point) is used as a proxy for flow stage. In addition, uncertainties in clay content of just $5 \%-10 \%$ percent are capable of creating scatter comparable to that in Fig. 2. Despite such large potential errors and the bias they may introduce into predictions of bank-full depths, the analysis presented here rules out the possibility that floodplain deposit clay contents and bank-full depths are related by chance (i.e., $p \sim 10^{-17}$ ), and it demonstrates that Eq. (5) predicts bank-full depths to within a factor of 2 of the observed bank-full depths for $84 \%$ of the 387 stations included in the analysis.

The model of this paper posits that bank-full depth may be self-regulated via a tendency for an increase in bank height caused by channel incision and/or floodplain deposition to trigger bank failure when a critical bank height, dependent on bank material cohesion, is exceeded. An important role for gravitational failure in controlling alluvial channel geometry is consistent with process-based studies of bank retreat, in which gravitational shear failure has been documented to occur frequently during the falling limbs of flood discharges when pore pressures tend to be highest (e.g., Casagli et al., 1999; Simon et al., 2000). An important role for shear failure in bank retreat is also consistent with Li et al.'s (2015) finding that bank-full depth correlates with fluid viscosity because viscosity controls the permeability of bank material and hence pore pressures and therefore susceptibility to gravitational shear failure. Fluvial erosion of the bank toe is still necessary to remove material slumped from the bank into the channel and likely plays an important role in driving bank retreat in channels with cantilevered banks (Pizzuto, 1994). However, if the bank is more than twice the height of the zone of scour, gravitational shear failure nevertheless will be the process by which the majority of material is removed from the bank (Tao et al., 2019). That said, gravitational failure and fluvial shear stresses act in concert in such a way that identifying which process is dominant may be difficult. Fluvial scour transports slumped material away from the bank, likely keeping bank angles higher than they would be without fluvial scour. Gravitational failure transports material from higher on the bank to the toe (often following fluvial scour, which is maximized at the toe), likely keeping bank angles lower than they would be without gravitational failure. More research is needed, but the relative importance of these two processes may be reflected in the bank angle; i.e., a bank angle that is persistently much lower than vertical may indicate the dominance of gravitational failure, while a bank angle persistently at or above $90^{\circ}$ (i.e., a cantilever or overhang) may indicate the dominance of fluvial scour.

Bank vegetation plays a significant role in controlling bank stability, but it is unlikely that such control is responsible for the scaling relationships that are the focus of this paper, as such scaling relationships exist across climatic regions with very different vegetation characteristics. In addition, the stability of any bank is primarily a function of its weakest portion or layer, i.e., failure is more likely to occur in a zone of low shear strength compared to a zone of high shear strength, all else being equal. Failure of a weaker zone underlying a stronger zone can create a cantilever, but such cantilevers cannot continue to grow indefinitely, hence rates of long-term retreat in stronger and weaker zones of the same bank will tend to be similar. This, together with the fact that vegetation is likely to strengthen only the uppermost $\sim 2 \mathrm{~m}$ of channel banks (globally, $>99 \%$ of roots are found in the upper- 


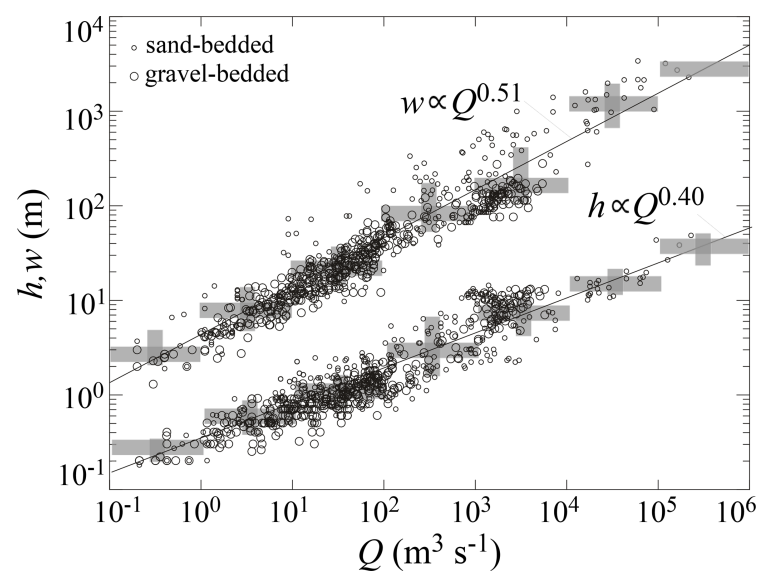

Figure 4. Plots of bank-full depth, $h$, and width, $w$, as a function of bank-full discharge, $Q$, from the Dunne and Jerolmack (2018) global dataset, along with least-squares linear regressions of the logarithms of the data, indicating $b=0.512 \pm 0.007$ and $k=0.402 \pm 0.006$ for this dataset.

most $2 \mathrm{~m}$ of the soil, Jackson et al., 1996), suggests that bank material shear strength is unlikely to be controlled primarily by vegetation in channels deeper than $2 \mathrm{~m}$. A dependence of bank retreat rates on vegetation has been documented in many studies (e.g., Ielpi and Lapôtre, 2020). However, such studies may not fully account for the fact that wetter climates with more vegetation also tend to have more clay-rich soils, leaving open the question of whether it is bank vegetation or material texture that is most responsible for bank resistance to erosion.

The model and analyses of this paper are simplified in at least five specific ways that bear mentioning. First, it does not account for tension cracks that, if present, can lower the maximum stable height below that predicted by Eq. (2) (Darby and Thorne, 1994). Second, it does not account for the role of vegetation in bank stability, which can increase bank heights by at least a factor of 2 over values predicted using bank material texture alone (Huang and Nanson, 1998). Third, it assumes a maximally incised channel, i.e., a channel that has incised to the point of reaching the threshold of bank stability quantified by Eq. (2). Quaternary climatic changes have driven cycles in which channel aggradation has been followed by a positive feedback of incision and channel narrowing (e.g., Bull, 1991) that have likely made many alluvial channels prone to an incised state. Such considerations, however, do not apply to some types of alluvial channels, e.g., small-scale channels formed in the laboratory and those in which sediment supply is not heavily influenced by climatic changes. Fourth, it involves no explicit constraint on the width-to-depth ratio of alluvial channels despite the fact that such a constraint may play an important role in some cases. An important concept in rill erosion is that unit stream power is maximized for a width-to-depth ratio of $\approx 0.5-3$, with the specific value dependent on the cross-sectional func-

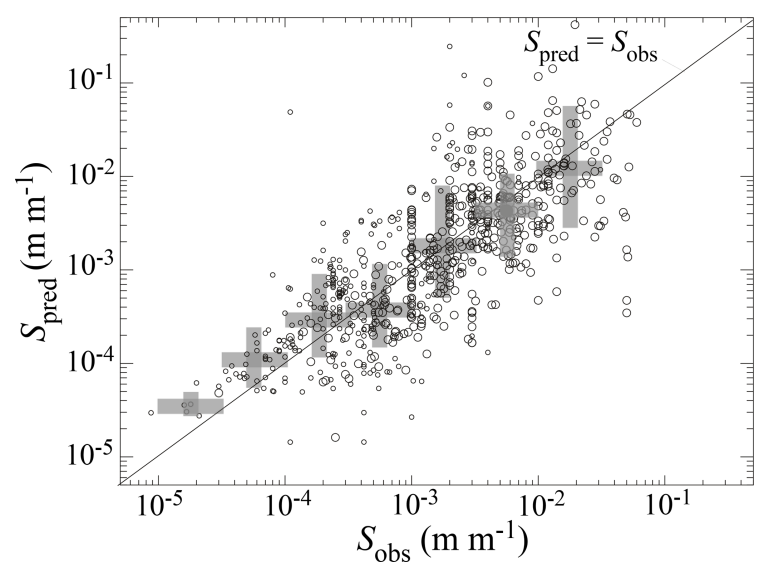

Figure 5. Plot of predicted along-channel slope, $S_{\text {pred, }}$ using Eqs. (16) and (20) as a function of observed along-channel slope, $S_{\text {obs }}$, in the Dunne and Jerolmack (2018) global dataset. Predicted values for sand-bedded channels assume $\tau_{\mathrm{c}} / \tau_{0} \approx 0$ (consistent with the suspended-load-dominated conditions common in sand-bedded channels, Dade and Friend, 2000) and $\alpha \approx 0.05$ (Guy et al., 1966).

tional form (e.g., Moore and Burch, 1986). A similar concept may limit incision in channels with small width-to-depth ratios (Huang and Nanson, 2000), reducing the likelihood of channels with $w / h 1$ and hence potentially limiting $h$ to values smaller than that set by Eq. (2) for channels with small discharges. Such a control does not seem likely in the channels of the D\&J global dataset (since $w / h 10$ ), but it may play an important role in some types of channels and should be explicitly considered in future research. Fifth, the analysis assumes that the dominant sources of roughness in the channels of the D\&J data are ripples and dunes or gravel clasts. Longwavelength topographic features such as bars and meanders are not likely to be dominant roughness- or drag-inducing elements given that the presence or absence of the flow separation that tends to dominate drag depends sensitively on the maximum slope of bedforms and other obstacles to the flow, with slopes in excess of $0.2 \mathrm{~m} \mathrm{~m}^{-1}$ generally needed to trigger flow separation (e.g., Lefebvre et al., 2014). Vegetation can certainly be a dominant source of roughness on the beds of ephemeral channels, however, and some of the scatter in the analysis of this paper may be a result of vegetationinduced bed roughness.

More data on the relationship between bank cohesion and bank material texture are needed. This study used clay content as a predictive variable for cohesion in part because a transfer function is available between clay content and cohesion based on the work of Dafalla (2013) used in Fig. S1. However, silt content also affects cohesion (Huang et al., 2006) and the findings of Schumm (1960) suggest that both the silt and clay content of bank material are relevant to understanding alluvial channel geometry. The specific surface area of bank material may be a more accurate predictive variable for cohesion than either clay content or silt and clay con- 
tent (weighted equally), as specific surface area includes both the silt and clay contents but weighs the presence of clays more heavily (Huang et al., 2006).

The analysis presented here used a power-law relationship to quantify the relationship between $F$ and $Q$ (Eq. 7). However, a scaling break appears to exist in the D\&J global dataset (Fig. 3a), with $F$ values approximately constant for $Q$ values less than $\sim 10^{2} \mathrm{~m}^{3} \mathrm{~s}^{-1}$ (i.e., discharges dominated by gravel-bedded channels). This break may be consistent with the critical-flow hypothesis, i.e., steep, predominantly gravel-bedded channels in the D\&J global dataset may have $F$ values predominantly in the range of $0.3-1$, independent of channel size and discharge, because the general lack of ripples and dunes in gravel-bedded channels requires that the increase in drag near critical flow conditions be caused primarily by wave drag, while in sand-bedded channels the increase in drag near critical-flow conditions is likely to be caused by ripples and/or dunes that form at a range of Froude numbers weakly dependent on bank-full discharge. It would be useful for future research to investigate the relationships among $F$, $Q$, bed texture, and the presence or absence of ripples and/or dunes to more fully test this hypothesis and its implications for potential breaks in scaling within Eq. (1).

The model of this paper implicitly includes the sedimentsupply control on along-channel slope documented by $\mathrm{Li}$ et al. (2015), Pfeiffer et al. (2017) and Blom et al. (2017). Drainage basins with higher rates of sediment supply erode faster, resulting in coarser sediments being delivered to channels, all else being equal (Attal et al., 2015). Coarser sediments increase along-channel slopes because steeper slopes are necessary to achieve critical or near-critical water velocities in alluvial channels with coarser bed sediments (Eqs. 16 and 20).

\section{Conclusions}

This paper proposed that the bank-full depths of alluvial channels may be partially controlled by the maximum heights of gravitationally stable channel banks, which depend on bank material cohesion and hence on clay content. Bank-full depths predicted by a bank-stability model correlate with the observed bank-full depths estimated using the bends in the stage-discharge rating curves for 387 USGS gaging stations in the Mississippi River basin. It was proposed, inspired by the critical-flow hypothesis of Grant (1997), that depth-averaged water velocities scale with bankfull depths as a result of a self-regulatory feedback among water flow, relative roughness, and channel-bed morphology that limits velocities to be within a relatively narrow range associated with Froude numbers that have a weak inverse relationship to bank-full discharge. Given these constraints on channel depths and depth-averaged water velocities, bankfull widths and along-channel slopes consistent with observations follow from conservation of mass and energy of water flow. The model of this paper provides a novel processbased understanding of the hydraulic geometry of alluvial channel networks. A better understanding of how cohesion relates to bank material clay and/or silt contents; how channel depths and/or bank angles adjust to spatial variations in bank material cohesion through a channel network; and the relationships among bank-full discharges, bank-full Froude numbers, bed texture, and the presence or absence of ripples and/or dunes would enable a more comprehensive test of the model of this paper and a better understanding of the bank-textural controls on the hydraulic geometry of alluvial channels more generally. 


\section{Appendix A}

Table A1. List of variables.

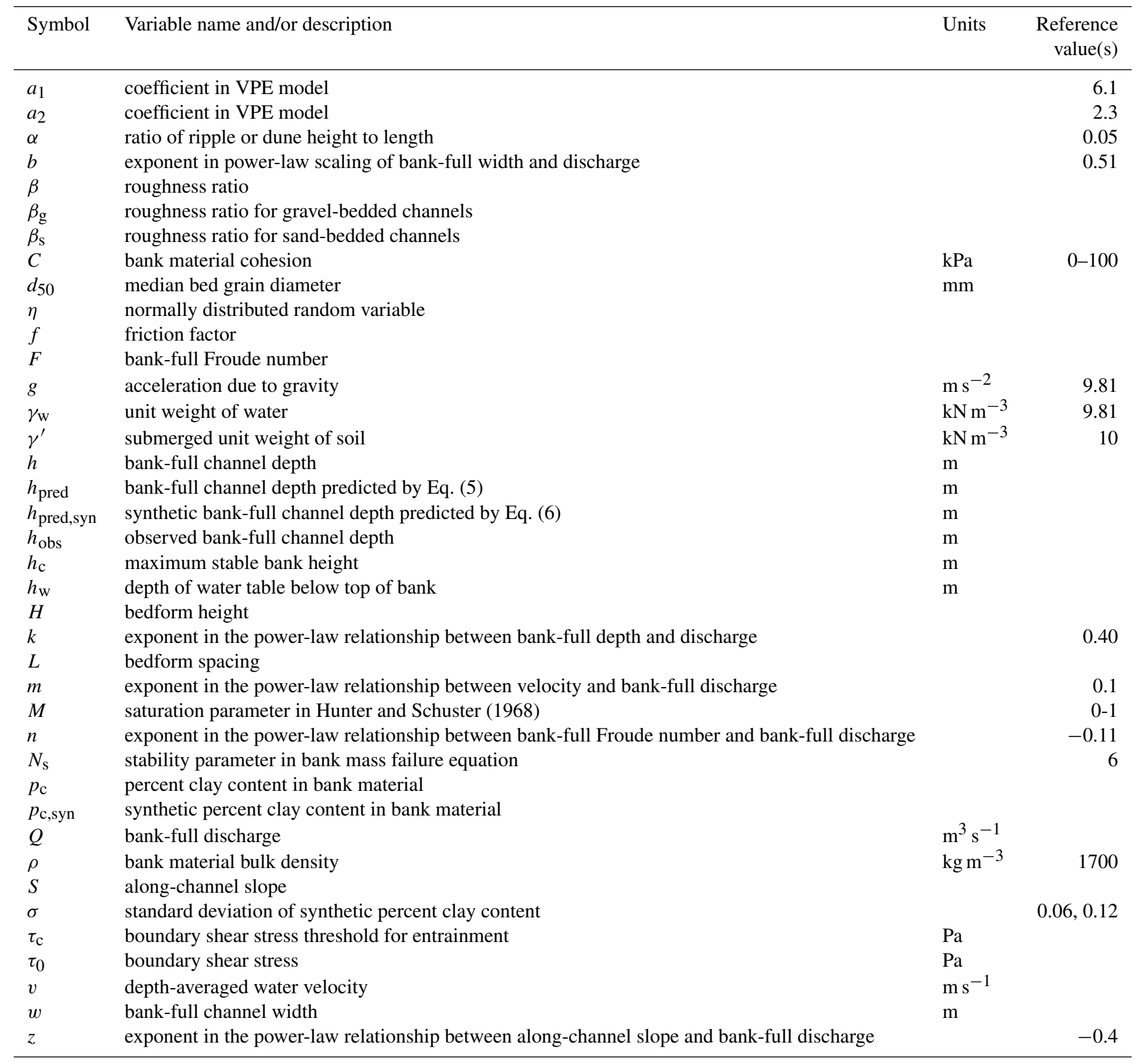


Data availability. The Supplement contains all of the data used in the paper not published elsewhere.

Supplement. The supplement related to this article is available online at: https://doi.org/10.5194/esurf-9-379-2021-supplement.

Author contributions. JDP performed all of the work presented in this work and wrote the manuscript.

Competing interests. The author declares that they have no conflict of interest.

Acknowledgements. I wish to thank Gordon Grant, Roberto Fernández, Christopher Hackney, Luke A. McGuire, and Alexander B. Prescott for careful reviews that led to a significantly improved manuscript.

Review statement. This paper was edited by Rebecca Hodge and reviewed by Gordon Grant, Christopher Hackney, and Roberto Fernández.

\section{References}

Andrews, E. D.: Bank stability and channel width adjustment, East Fork River, Wyoming, Water Resour. Res., 18, 1184-1192, https://doi.org/10.1029/WR018i004p01184, 1982.

Archuleta, C. M., Constance, E. W., Arundel, S. T., Lowe, A. J., Mantey, K. S., and Phillips, L. A.: The National Map seamless digital elevation model specifications, U.S. Geological Survey Techniques and Methods, 11, B9, https://doi.org/10.3133/tm11B9, 2017.

ASCE: Task Committee on Hydraulics, Bank Mechanics, and Modeling of River Width Adjustment, River width adjustment, 1. Processes and mechanisms, J. Hydraul. Eng., 124, 881-902, 1998.

Attal, M., Mudd, S. M., Hurst, M. D., Weinman, B., Yoo, K., and Naylor, M.: Impact of change in erosion rate and landscape steepness on hillslope and fluvial sediments grain size in the Feather River basin (Sierra Nevada, California), Earth Surf. Dynam., 3, 201-222, https://doi.org/10.5194/esurf-3-201-2015, 2015.

Bathurst, J. C.: Flow resistance through the channel network, in: Channel Network Hydrology, edited by: Beven, K., and Kirkby, M. J., Wiley, Chichester, U.K., 43-68, 1993.

Blom, A., Arkesteijn, L., Chavarrías, V., and Viparelli, E.: The equilibrium alluvial river under variable flow and its channelforming discharge, J. Geophys. Res.-Earth, 122, 1924-1948, https://doi.org/10.1002/2017JF004213, 2017.

Bull, W. B.: Geomorphic Responses to Climatic Change, Oxford University Press, 326 pp., 1991.

Casagli, N., Rinaldi, M., Gargini, A., and Curini, A.: Pore water pressure and streambank stability: results from a monitoring site on the Sieve River, Italy, Earth Surf. Proc. Land., 24, 1095-1114, https://doi.org/10.1002/(SICI)10969837(199911)24:12<1095::AID-ESP37>3.0.CO;2-F, 1999.
Chen, W. F., Giger, M. W., and Fang, H. Y.: On the limit analysis of stability of slopes, Soils Found., 9, 23-32, https://doi.org/10.3208/sandf1960.9.4_23, 1969.

Copeland, R. R., Biedenharn, D. S., and Fischenich, J. C.: ChannelForming Discharge, U.S. Army Corps of Engineers Technical Note ERDC/CHL CHETN-VIII-5, 10 pp., 2000.

Dade, W. B. and Friend, P. F.: Grain-size, sediment-transport regime, and channel slope in alluvial rivers, J. Geol., 106, 661676, https://doi.org/10.1086/516052, 1998.

Dafalla, M. A.: Effects of clay and moisture content on direct shear tests for clay-sand mixtures, Adv. Mater. Sci. Eng., 2013, 562726, https://doi.org/10.1155/2013/562726, 2013.

Darby, S. E. and Thorne, C. R.: Prediction of tension crack location and riverbank erosion hazards along destabilized channels, Earth Surf. Proc. Land., 19, 233-245, https://doi.org/10.1002/esp.3290190304, 1994.

Dong, T. Y., Nittrouer, J. A., Czapiga, M. J., Ma, H., McElroy, B., Il'icheva, E., Pavlov, M., Chalov, S., and Parker, G.: Roles of bank material in setting bankfull hydraulic geometry as informed by the Selenga River Delta, Russia, Water Resour. Res., 55, 827 846, https://doi.org/10.1029/2017WR021985, 2019.

Dunne, K. B. J. and Jerolmack, D. J.: Evidence of, and a proposed explanation for, bimodal transport states in alluvial rivers, Earth Surf. Dynam., 6, 583-594, https://doi.org/10.5194/esurf-6-5832018, 2018.

Dunne, K. B. J. and Jerolmack, D. J.: What sets river width?, Sci. Adv., 6, eabc1505, https://doi.org/10.1126/sciadv/abc1505, 2020.

Eaton, B. C. and Millar, R. G.: Optimal alluvial channel width under a bank stability constraint, Geomorphology, 62, 35-45, https://doi.org/10.1016/j.geomorph.2004.02.003, 2004.

Ferguson, R. I.: Hydraulics and hydraulic geometry, Prog. Phys. Geogr., 10, 1-31, https://doi.org/10.1177/030913338601000101, 1986.

Ferguson, R. I.: Flow resistance equations for gravel- and boulder-bed streams, Water Resour. Res., 43, W05427, https://doi.org/10.1029/2006WR005422, 2007.

Grant, G. E.: Critical flow constrains flow hydraulics in mobile-bed streams: A new hypothesis, Water Resour. Res., 33, 349-358, https://doi.org/10.1029/96WR03134, 1997.

Guy, H. P., Simons, D. B., and Richardson, E. V.: Summary of alluvial channel data from flume experiments, 1956-1961, U.S. Geological Survey Professional Paper, 462, 1-96, 1966.

Huang, H. Q. and Nanson, G. C.: The influence of bank strength on channel geometry: An integrated analysis of some observations, Earth Surf. Proc. Land., 23, 865-876, https://doi.org/10.1002/(SICI)10969837(199810)23:10<865::AID-ESP903>3.0, 1998.

Huang, H. Q. and Nanson, G. C.: Hydraulic geometry and maximum flow efficiency as products of the principle of least action, Earth Surf. Proc. Land., 25, 1-16, https://doi.org/10.1002/(SICI)1096-9837(200001)25:1<1::AIDESP68>3.0.CO;2-2, 2000.

Huang, H. Q., Chang, H. H., and Nanson, G. C.: Minimum energy as the general form of critical flow and maximum flow efficiency and for explaining variations in river channel pattern, Water Resour. Res., 40, W04502, https://doi.org/10.1029/2003WR002539, 2004. 
Huang, J., Hilldale, R. C., and Griemann, B. P.: Chapter 4: Cohesive Sediment Transport, in Erosion and Sedimentation Manual, U.S. Department of Interior Bureau of Reclamation, Denver, Colorado, 46 pp., 2006.

Hunter, J. H. and Schuster, R. L.: Stability of simple cuttings in normally consolidated clays, Geotechnique, 3, 372-378, 1968.

Ielpi, A. and Lapotre, M.: A tenfold slowdown in river meander migration driven by plant life, Nat. Geosci., 13, 82-86, https://doi.org/10.1038/s41561-019-0491-7, 2020.

Jackson, R. B., Canadell, J., Ehleringer, J. R., Mooney, H. A., Sala, O. E., and Schulze, E. D.: A global analysis of root distributions for terrestrial biomes, Oecologia, 108, 389-411, https://doi.org/10.1007/BF00333714, 1996.

Knighton, A. D.: Variation in width-discharge relation and some implications for hydraulic geometry, Geol. Soc. Am. Bull., 85, 1069-1076, https://doi.org/10.1130/00167606(1974)85<1069:VIWRAS>2.0.CO;2, 1974.

Lefebvre, A., Paarlberg, A. J., Ernstsen, V. B., and Winter, C.: Flow separation and roughness lengths over large bedforms in a tidal environment: A numerical investigation, Cont. Shelf Res., 91, 57-69, https://doi.org/10.1016/j.csr.2014.09.001, 2014.

Leopold, L. B. and Maddock Jr., T.: The Hydraulic Geometry of Stream Channels and Some Physiographic Implications, U.S. Geological Survey Professional Paper 252, 57 pp., 1953.

Li, C., Czapiga, M. J., Eke, E. C., Viparelli, E., and Parker, G.: Variable Shields number model for river bankfull geometry: bankfull shear velocity is viscosity-dependent but grain size-independent, J. Hydraul. Res., 53, 36-48, https://doi.org/10.1080/00221686.2014.939113, 2015.

Lindley, E. S.: Regime channels. Proceedings, Punjab Engineering Congress, 7, 63-74, 1919.

Miller, D. A. and White, R. A.: A Conterminous United States Multi-Layer Soil Characteristics Data Set for Regional Climate and Hydrology Modeling, Earth Interactions, 2, 2, https://doi.org/10.1175/10873562(1998)002<00013AACUSMS> 2.3.CO3B2, 1998.

Moore, I. D. and Burch, G. J.: Sediment transport capacity of sheet and rill flow: Application of unit stream power theory, Water Resour. Res., 22, 1350-1360, https://doi.org/10.1029/WR022i008p01350, 1986.

Nardi, F., Annis, A., Di Baldassarre, G., Vivoni, E. R., and Grimaldi, S.: GFPLAIN $250 \mathrm{~m}$, a global high-resolution dataset of Earth's floodplains, Scientific Data, 6, 180309, https://doi.org/10.1038/sdata.2018.309, 2019.

Ohata, K., Naruse, H., Yokokawa, M., and Viparelli, E.: New bedform phase diagrams and discriminant functions for formative conditions of bedforms in open-channel flows, J. Geophys. Res.Earth, 122, 2139-2158. https://doi.org/10.1002/2017JF004290, 2017.
Parker, G.: Hydraulic geometry of active gravel rivers, Journal of the Hydraulics Division of the America Society of Civil Engineers, 105, 1185-1201, 1979.

Pfeiffer, A. M., Finnegan, N. J., and Willenbring, J. K.: Sediment supply controls equilibrium channel geometry in gravel rivers, P. Natl. Acad. Sci. USA, 114, 3346-3351, https://doi.org/10.1073/pnas.1612907114, 2017.

Pizzuto, J.: Equilibrium bank geometry and the width of shallow sandbed streams, Earth Surf. Proc. Land., 9, 199-207, 1994.

Ramcharan, A., Hengl, T., Nauman, T., Brungard, C., Waltman, S., Wills, S. and Thompson, J.: Soil Property and Class Maps of the Conterminous United States at 100-Meter Spatial Resolution, Soil Sci. Soc. Am. J., 82, 186-201, https://doi.org/10.2136/sssaj2017.04.0122, 2018.

Schumm, S. A.: The shape of alluvial channels in relationship to sediment type, U.S. Geological Survey Professional Paper 352B, 1960.

Simon, A., Curini, A., Darby, S. E., and Langendoen, E. J.: Bank and near-bank processes in an incised channel, Geomorphology, 35, 193-217, 2000.

Simons, D. B. and Richardson, E. V.: Resistance to Flow in Alluvial Channels, U.S. Geological Survey Professional Paper 422-J, U.S. Government Printing Office, Washington, D.C., 1966.

Singh, V. P.: On the theories of hydraulic geometry, Int. J. Sed. Res., 18, 196-218, 2003

Smith, T. R.: A derivation of the hydraulic geometry of steadystate channels from conservation principles and sediment transport laws, J. Geol., 82, 98-104, https://doi.org/10.1086/627939, 1974.

Soil Survey Staff: Gridded National Soil Survey Geographic (gNATSGO) Database for the Conterminous United States. United States Department of Agriculture, Natural Resources Conservation Service, available at: https://nrcs.app.box.com/v/ soils (last access: 30 April 2020), 2019.

Tao, G., Chen, J., and Pan, Y.: An improved analysis model for cantilever failure of composite riverbanks and collapse simulation, IOP Conference Series, Earth Environ. Sci., 304, 032045, https://doi.org/10.1088/1755-1315/304/3/032045, 2019.

Taylor, D. W.: Stability of earth slopes, Journal of the Boston Society of Civil Engineers, 24, 197-246, 1937.

Terzaghi, K. and Peck, R. B.: Soil Mechanics in Engineering Practice, John Wiley and Sons, Inc., New York, 579 pp., 1967.

U.S. Geological Survey: Peak Streamflow for the Nation, Digital data available at: https://nwis.waterdata.usgs.gov/usa/nwis/peak, last access: 30 April 2020.

Wohl, E.: Mountain Rivers Revisited, John Wiley \& Sons, New York, 609 pp., 2013.

Yalin, M. S.: Geometrical properties of sand wave, Journal of Hydraulic Division of the American Society of Civil Engineering, 90, 105-119, 1964. 